Hazards of the job

\section{World at work: Refuse collectors}

\section{P P F M Kuijer, M H W Frings-Dresen}

\section{A discussion of risks of the job and measures to protect the workers}

$\mathrm{R}$ efuse is collected all around the world. The following collecting methods are mentioned in the literature: ${ }^{1}$ bags (plastic and paper), bins (110-150 l), drums (110-210 l), twowheeled containers (80-360 l), and four-wheeled containers (300-1800 l). Over all, the job of a refuse collector can be characterised by frequent lifting, carrying, pushing, and/or pulling of heavy objects. In the Netherlands, most production systems to collect domestic refuse make use of a closed refuse truck with an automatic lifting device to empty two-wheeled containers (fig 1) or four-wheeled containers (fig 2). ${ }^{23}$ Only in a few parts of the Netherlands, especially in city areas where households have no space to place a container, are bags collected. ${ }^{4}$ In general, the wheeled containers are collected by a team of a truck driver and one or two refuse collectors. Table 1 presents the time spent on the different tasks and activities. ${ }^{2}$ An average work day of a refuse collector lasts about 8 hours (range 6-12). A refuse collector of twowheeled containers collects about $11000 \mathrm{~kg}$ of refuse per day, and a refuse collector of four-wheeled containers about $14000 \mathrm{~kg}$. This is about 500 (22 kg of refuse per container) twowheeled containers and $130(110 \mathrm{~kg}$ of refuse per container) four-wheeled containers each day. In general, a refuse collector pushes and pulls one twowheeled container at a time. Pulling of the two-wheeled container is often done with one hand behind the back. A fourwheeled container is in general transferred by two persons. ${ }^{2}$

The work is mainly performed by male employees, although there are also some female employees in the Netherlands. The aerobic power of a refuse collector does not differ from workers without physically demanding tasks. ${ }^{5}$ Refuse collectors seem to have larger muscle strength compared to workers without physically demanding tasks. This may be due to a training effect or due to "a healthy worker selection effect" ${ }^{\prime \prime}{ }^{5}$

\section{HAZARDS OF THE JOB AND IN THE WORKPLACE Occupational accidents}

Refuse collectors are at a high risk for fatal and non-fatal occupational accidents. In 1998 the United States Bureau of Labor Statistics reported that US refuse collectors experienced 48.8 fatalities per 100000 workers in 1996, and that refuse collecting was the seventh riskiest occupation in the USA. $^{6}$ An analysis over the period 1992-97 yielded an occupational fatality rate of 46 per 100000 refuse collectors. This rate is about 10 times higher than the overall fatality rate in the USA. ${ }^{7}$ For instance, in 1998 the US Bureau of Labour Statistics showed that 42 refuse collectors were killed on the job in 1998. ${ }^{7}$ Trans-

portation incidents accounted for about $70 \%$ of these deaths. The second most important cause of death (19\%) was "contact with object/equipment". In Denmark, no fatal accidents were reported in the period 1989-92. ${ }^{1}$ No other data on fatal accidents were found. For non-fatal accidents, the incidence rate of occupational accidents was at least 95 per 1000 employees per year among Danish refuse collectors and 17 per 1000 in the total workforce according to the Danish Registry of Occupational Accidents and Diseases. ${ }^{1}$ A more detailed study at a single Danish company in 1993 showed that of the 667 employees, 114 experienced an injury: an incidence rate of occupational accidents of 170 per 1000 employees per year. ${ }^{8}$ Another Danish study reported 178 accidents among 210 refuse collectors in 1992: an incidence rate of occupational accidents of 847 per 1000 employees per year. ${ }^{1}$ For the USA, Dorevitch and Marder ${ }^{7}$ reported the number of compensation claims for the municipal refuse collectors in Cincinatti in the period 1965-67 and of two private companies in San Francisco in 1982: 284 and 467 , respectively. Unfortunately, no data are presented of the population at risk. In Brazil, a study performed in a medium sized town of about 500000 inhabitants reported 103 occupational accidents among 81 refuse collectors over a period of 12 months: an incidence rate of more than 1200 per 1000 employees per year. ${ }^{9}$ Another Brazilian study reported an incidence rate of occupational accidents of about 700 per 1000 refuse collectors per year. ${ }^{1}$

The type of injuries and the causes seem to vary by country, based on studies from Brazil, ${ }^{9}{ }^{10}$ Denmark, ${ }^{8}$ Taiwan, ${ }^{11}$ and the USA. ${ }^{67}$ For instance, the percentage of fractures among the medical diagnoses of the occupational accidents seems to be higher in Brazil (5\%) and the USA (5-7\%) than in Denmark (1\%). No data were available in the Taiwanese study. Also, the percentage of cutting injuries among the causes of the occupational accidents seems to be much higher in Brazil (29$31 \%)$, Taiwan (" $37 \%$ of the refuse collectors had a injury caused by a sharp object in the last 12 months"), and the USA (11-31\%) than in Denmark (4\%). In general, the body parts most often injured were the back, arms, and legs. In the different studies, the injury types mentioned in more than $10 \%$ of the cases were strains/sprains, contusion, cutting injury, tenosynovitis, laceration, twisting, and soft part injury. The causes mentioned in more than $10 \%$ of the cases were "fall or slip injury", "struck or injured by goods, vehicles or objects", "cutting or perforating objects", and "overloading of the body". One study showed a decrease in the number of injuries with increasing seniority. ${ }^{8}$ In a Canadian study, about the same result was found. ${ }^{12}$

\section{Musculoskeletal complaints}

Studies on health complaints among refuse collectors in Brazil, ${ }^{10}$ Denmark, ${ }^{1813}$ Taiwan, ${ }^{11}$ the Netherlands, ${ }^{14}{ }^{15}$ and the $U_{S A^{67}}$ reported an increased risk for musculoskeletal complaints. The body region most affected is the low back. Other frequent affected areas are the shoulder, knee, and neck, depending on the method of collection. The high biomechanical workload in refuse collecting is seen as an important risk factor for these musculoskeletal complaints. The following risk factors are present.

\section{Lifting}

A study on the biomechanical workload while lifting an empty four-wheeled container from the street to the sidewalk showed that peak compression forces on the low back exceeded the NIOSH limit of $3400 \mathrm{~N}$ by far. ${ }^{16}$ The same kind of results were found for lifting of bags, bins, and drums. ${ }^{16} 17$

\section{Pushing and pulling}

Studies on the biomechanical workload during pushing and pulling of twowheeled and four-wheeled containers reported relatively low compression forces on the low back, varying between about $400 \mathrm{~N}$ and $2800 \mathrm{~N} .{ }^{16-19}$ Only in the case that a four-wheeled container with a total weight of $385 \mathrm{~kg}$ was pulled ${ }^{16}$ and a two-wheeled container with a total weight of $74 \mathrm{~kg}$ was pulled and 


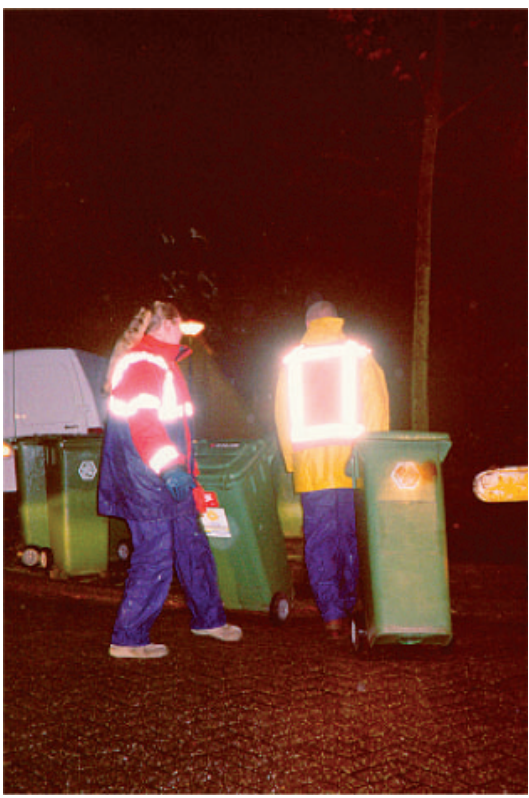

Figure 1 Collecting of two-wheeled containers.

pushed, ${ }^{19}$ was the NIOSH criterion of $3400 \mathrm{~N}$ exceeded. Two studies also quantified the shoulder load while collecting two-wheeled containers. ${ }^{17}{ }^{19}$ Although no comparable limit exists for shoulder load as for low back load, both studies rated the shoulder load as relatively low during pushing and pulling. Despite the low intensity of the low back and shoulder load, work practise guidelines regarding push and pull forces are exceeded. ${ }^{19}$ Moreover, pushing and pulling of containers is performed day after day, year after year. Besides, pushing and pulling is seen as a risk factor for shoulder complaints rather than for low back complaints. ${ }^{20}$

\section{Whole body vibration}

Whole body vibration is seen as an important risk factor for back complaints. $^{21}$ Not only the truck driver, but also the refuse collectors are exposed to whole body vibration while sitting in the refuse truck or standing on the riding steps at the back of the truck. Unfortunately, no specific study was found that actually quantified the exposure for driving a refuse truck. The exposure might be higher than in a normal truck due to, for instance, the mechanical system that empties the wheeled container, the mechanical compression of the collected refuse in the cargo space, and the fact that city streets are often less smooth than asphalt roads.

\section{Fatigue complaints}

Several studies from different countries reported that the energetic workload

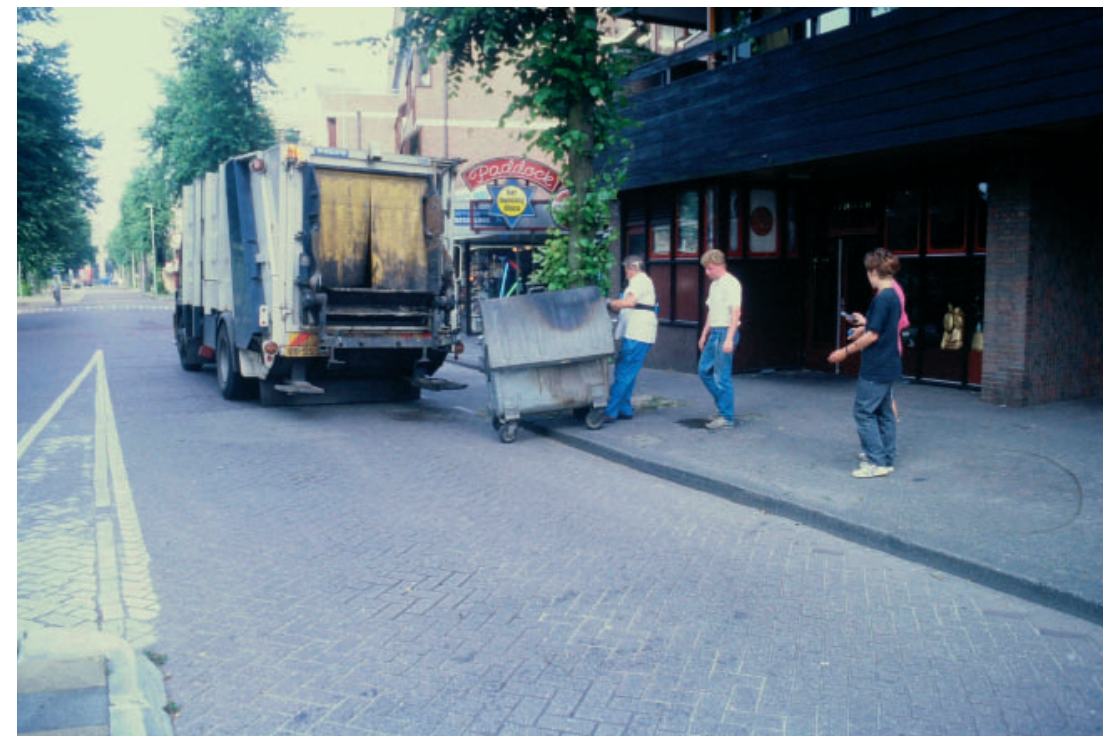

Figure 2 Collecting of a four-wheeled container. limit of $30 \% \quad \dot{\mathrm{V}} \mathrm{O}_{2 \max }$ for an eight hour working day is exceeded for collecting two-wheeled containers and for collecting bags and bins..$^{1-422} 23$ In general, the energetic workload is higher during the collecting of bags and bins than during the collecting of two-wheeled and four-wheeled containers. In the Netherlands, the energetic workload limit is not exceeded for collecting four-wheeled containers. ${ }^{2}$ Despite these results, no studies were found on fatigue complaints on a long term basis.

\section{Respiratory complaints}

Refuse collectors have an increased risk of respiratory and influenza like symptoms. ${ }^{124}{ }^{25}$ Refuse collectors are exposed to microbial agents, irrespective of the refuse they collect. Despite the low levels of exposure, a respiratory inflammatory response is measurable. ${ }^{26}$ Exposure to fungal spores, $\beta(1 \rightarrow 3)$-glucans, and endotoxin probably results in the respiratory inflammatory response. ${ }^{27}$ The implications of chronic inflammation in the nose and subsequent nasal symptoms are not yet known but need to be established. ${ }^{26} 27$

\section{Gastrointestinal complaints}

A high frequency of gastrointestinal problems has been reported for refuse collectors, ${ }^{125}$ especially in the summer. ${ }^{28}$ The wet biological fractions of refusethat is, garden waste, and the degradable fraction of household refuse, are responsible. An exposure-response relation was found among refuse collectors between nausea and endotoxin exposure, and between diarrhoea and exposure to both endotoxins and viable fungi. $^{29}$

\begin{tabular}{|c|c|c|c|c|}
\hline & \multicolumn{2}{|c|}{ Two-wheeled containers } & \multicolumn{2}{|c|}{ Four-wheeled containers } \\
\hline & Mean & SD & Mean & SD \\
\hline \multicolumn{5}{|l|}{ Tasks (minutes) } \\
\hline Collecting & 287 & 57 & 342 & 30 \\
\hline Driving & 78 & 27 & 100 & 9 \\
\hline Dumping & 11 & 9 & 13 & 9 \\
\hline Pausing & 99 & 29 & 62 & 9 \\
\hline \multicolumn{5}{|l|}{ Activities (minutes) } \\
\hline Standing & 70 & 28 & 65 & 8 \\
\hline Walking & 68 & 22 & 61 & 8 \\
\hline Sitting & 158 & 136 & 256 & 30 \\
\hline Handling of bags & 1 & 1 & 6 & 1 \\
\hline Pushing full container & 27 & 9 & 6 & 2 \\
\hline Pushing empty container & 6 & 5 & 3 & 2 \\
\hline Pulling full container & 27 & 12 & 12 & 2 \\
\hline Pulling empty container & 20 & 8 & 8 & 3 \\
\hline
\end{tabular}


Table 2 The Dutch guideline for refuse collectors of two-wheeled containers, subdivided in three age categories

\begin{tabular}{llll}
\hline $\begin{array}{l}\text { Age of the refuse } \\
\text { collector }\end{array}$ & $\begin{array}{l}\text { Maximum amount of } \\
\text { refuse }(\mathbf{k g})\end{array}$ & $\begin{array}{l}\text { Maximum number of two- } \\
\text { wheeled containers }\end{array}$ & $\begin{array}{l}\text { Maximum number of } \\
\text { hours collecting }\end{array}$ \\
\hline$<30$ years & 11300 & 514 & 5.5 \\
$30-39$ years & 8300 & 377 & 4.0 \\
$>39$ years & 5200 & 236 & 2.5 \\
\hline
\end{tabular}

The maximum amount of refuse, the maximum number of two-wheeled containers, and the maximum number of hours collecting, may not be exceeded during an eight hour working day.

\section{Hearing complaints}

The noise limit of $80 \mathrm{~dB}(\mathrm{~A})$ for an eight hour working day was exceeded while collecting refuse in the Netherlands. ${ }^{14}$ The average noise level (SD) for collecting two-wheeled containers, fourwheeled containers, and bags was 94.7 $\mathrm{dB}(\mathrm{A})$ (2.9), $96.4 \mathrm{~dB}(\mathrm{~A})$ (1.5), and 92.4 $\mathrm{dB}(\mathrm{A})$ (5.3), respectively. In the same study, about $85 \%$ of the refuse collectors of two-wheeled containers, $50 \%$ of the refuse collectors of four-wheeled containers, and $65 \%$ of the refuse collectors of bags complain about the high noise level. No study has been found that quantified the hearing loss among refuse collectors.

\section{MEASURES TO PROTECT THE WORKER}

\section{Measures to increase safety}

There are numerous safety measures, for instance: ${ }^{7-9}$

- Reduction in working speed

- Training and instruction of refuse collectors

- Protective clothing (including retro reflective striping) and shoes

- Properly positioned riding steps, that are slip resistant, strong enough, and large enough, and properly placed grab handles should be present

- Camera on the back of the refuse truck to maintain visual contact between the driver and the collectors

- Automatic speed reduction to $30 \mathrm{~km}$.hour ${ }^{-1}$ while a refuse collector is standing on the riding step at the back of the truck

- An audible warning when the truck is operating in reverse

- Regulations and administrative control.

\section{Measures to reduce the risk of musculoskeletal and/or fatigue complaints}

The following measures to reduce the physical workload among refuse collectors have been evaluated and seem to be effective:

- Job specific guideline for refuse collectors regarding maximum produc-

- Job rotation between collecting bags, sweeping streets, and driving a sweeping machine ${ }^{31}$

- Job rotation between collecting twowheeled containers and driving a refuse truck ${ }^{15}$ tion limits (table 2 ) $^{30}$

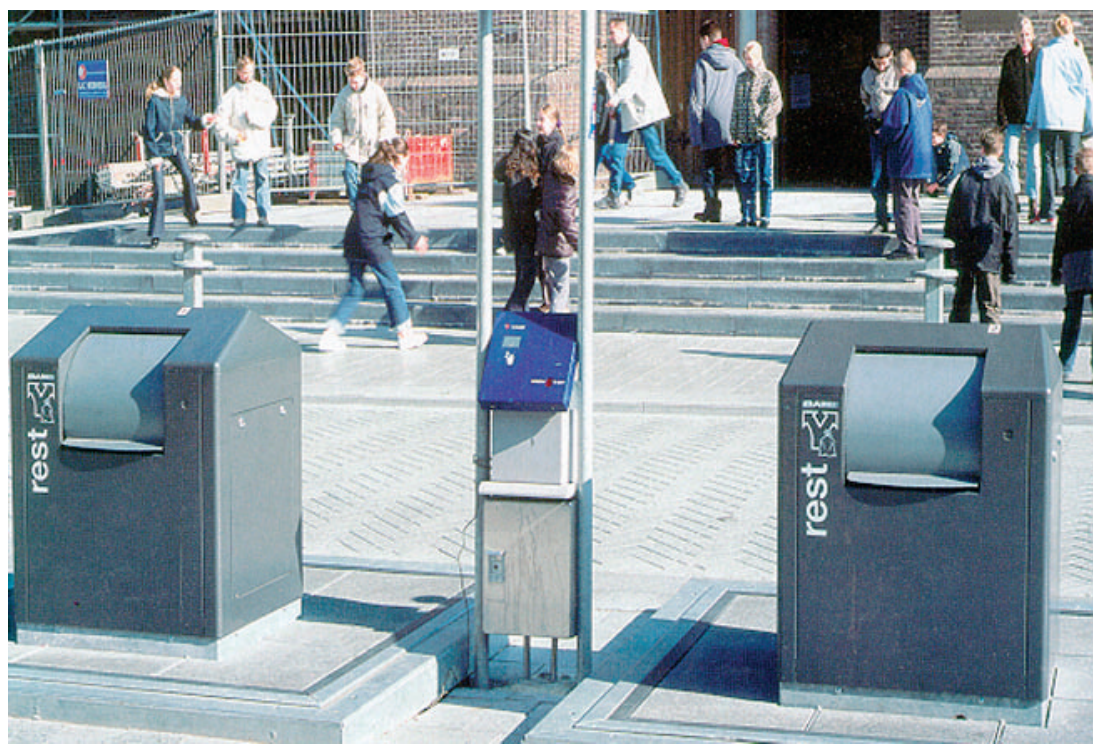

Figure 3 An example of an underground storage system.
- Replacement of bags and bins with wheeled containers ${ }^{16} 17$

- Increasing the number of twowheeled containers at a refuse collecting point from 2 to 16 or $32^{32}$

- Removing kerbs or obstacles at places where wheeled containers are collected $^{19}$

- Surfaces of flagstones instead of paving stones or grass at places where wheeled containers are collected ${ }^{18}$

- A two-wheeled container with a centre of mass closer to the wheel axis, larger wheels and higher handles compared to a standard twowheeled container ${ }^{19} 33$

- Transferring a four-wheeled container by two persons instead of one ${ }^{16}$

- At least a 10 minute rest break per hour while collecting four-wheeled containers. $^{34}$

An intervention that reduces both peak and cumulative load is probably most effective to prevent the onset of complaints.

\section{Measures to reduce the risk of respiratory and gastrointestinal complaints}

- Prevention of exposure can be achieved by using refuse trucks with a high loading for two-wheeled and four-wheeled containers. When the scoop is situated on the top (about 4 metres above the ground), the "cloud" of organic dust is well away from the breathing zone of the refuse collectors and their personal exposure to microorganisms is low. Reducing the exposure by means of job rotation between collecting and driving is not seen as an adequate measure.

\section{Measures to reduce the risk of hearing complaints}

- In the Netherlands, employees are obliged to wear personal protective hearing devices above noise levels of $85 \mathrm{~dB}(\mathrm{~A})$. By using custom moulded hearing protectors with an adequate attenuation filter, so called otoplastics, communication is still possible and other relevant sounds, for instance of traffic, can still be heard.

\section{New collection methods}

In recent years, two promising new collecting methods have been introduced, namely an underground storage system (fig 3) and an automated collection system of two-wheeled containers (fig 4). The underground storage system is a sort of dustbin on the street with a large depot underground. Citizens carry their own refuse to the underground 


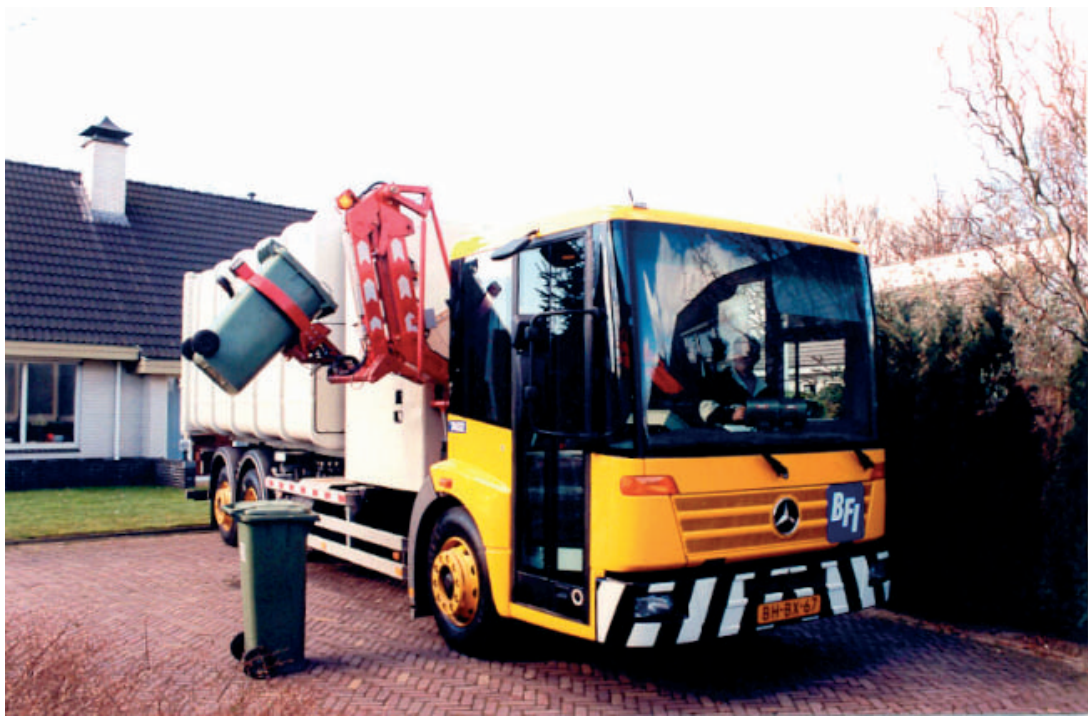

Figure 4 An example of a refuse truck with an automatic side collection system.

storage system. The large depots are emptied with the use of a crane on a refuse truck. In the automated collection system of two-wheeled containers, a mechanical arm on the refuse truck picks up a two-wheeled container, empties it, and puts it back on the street. In some cases, a refuse collector walks beside the refuse truck to position the two-wheeled containers in the right way. In general, these new production systems can be considered huge improvements with respect to physical, respiratory, and auditory work demands. However, these new ways of collecting also bring new health risks. Frequent joy-stick use to position the mechanical arm and the crane may increase the risk of work related upper extremity disorders. The increase in the time driving may increase the risk of back complaints due to whole body vibration. Moreover, a solitary function

\section{Main messages}

- Refuse collectors are at risk for fatal and non-fatal occupational accidents.

- Refuse collectors have an increased risk for musculoskeletal and hearing disorders due to the high physical workload and the high noise levels.

- Refuse collectors have an increased risk of respiratory and gastrointestinal complaints due to exposure to microbial agents in the organic dust. The long term effects are still unknown. as a driver/operator may lead to complaints due to an increased psychosocial workload.

\section{Periodic health surveillance}

Despite the initiatives to further improve the working conditions, it is unlikely that all health risks can be eliminated. Specific occupational demands remain present in the job of refuse collector. ${ }^{35}$ Therefore, specific periodic health surveillance (PHS) for refuse collectors has been developed in the Netherlands. The aim of the PHS is on the one hand to detect early signs of work related disease and on the other hand to monitor the work ability of the refuse collector on a regular basis. The PHS consists of: (1) a questionnaire concerning work ability, work demands, occupational hazards, and related health complaints such musculoskeletal and respiratory disorders; (2) general health tests such as tests for measuring the pulmonary function, blood pressure, hearing, and seeing; and (3) specific tests to measure the physical workload

\section{Policy implications}

- To reduce the risk of occupational accidents and work related diseases, several effective and feasible measures are available.

- A job specific periodic health surveillance for refuse collectors should be obligatory to detect early signs of work related disease and to monitor the work ability of the refuse collector. during the working day on the basis of the heart rate and to establish the maximum voluntary lift and pull strength. $^{35}$ The PHS should be performed at entrance and at least every four years for refuse collectors of 18 years and older, and at least every two years for refuse collectors of 52 years and older. This is in agreement with PHS regulations in the Dutch building industry.

Occup Environ Med 2004;61:282-286. doi: 10.1136/oem.2002.001172

\section{Authors' affiliations}

P P F M Kuijer, Monique H W Frings-Dresen, Coronel Institute for Occupational and Environmental Health, AmCOGG: Center for Research into Health and Health Care, Academic Medical Center/University of Amsterdam, Netherlands

Correspondence to: Dr P Kuijer, Coronel Institute for Occupational and Environmental Health, Academic Medical Centre/University of Amsterdam, PO Box 22700, $1100 \mathrm{DE}$

Amsterdam, Netherlands; p.p.kuijer@amc.uva.nl

\section{REFERENCES}

Poulsen OM, Breum NO, Ebbehoj N, et al. Collection of domestic waste. Review of occupational health problems and their possible causes. Sci Total Environ 1995:170:1-19.

2 Frings-Dresen MHW, Kemper HCG, Stassen ARA, et al. The daily work load of refuse collectors working with three different collecting methods: a field study. Ergonomics 1995:38:2045-55.

3 Kuijer PPFM, Frings-Dresen MHW, De Looze MP, et al. Work situation and physical workload of refuse collectors in three different time periods. Int J Ind Ergon 2000;26:509-19.

4 Kemper HCG, Van Aalst R, Leegwater A, et al. The physical and physiological workload of refuse collectors. Ergonomics 1990;33:1471-86.

5 Schibye B, Hansen AF, Sogaard K, et al. Aerobic power and muscle strength among young and elderly workers with and without physically demanding work tasks. Appl Ergon 2001;32:425-31

6 An H, Englehardt J, Fleming L, et al. Occupational health and safety amongst municipal solid waste workers in Florida. Waste Management \& Research 1999;17:369-77.

7 Dorevitch S, Marder D. Occupational hazards of municipal solid waste workers. Occup Med 2001; 16:125-33.

8 Ivens UI, Lassen JH, Kaltoft BS, et al. Injuries among domestic waste collectors. Am J Ind Med 1998;33:182-9.

9 Robazzi MLCC, Moriya TM, Favero M et al. Garbage collectors: occupational accidents and coefficients of frequency and severity per accident. Ann Agric Environ Med 1997;4:91-6.

10 Pimenta Velloso M, Moreira dos Santos E Antonio dos Anjos L. The labor process and workrelated accidents among garbage collectors in Rio de Janeiro, Brazil [in Portuguese]. Cad Saúde Pública, Rio de Janeiro 1997;13:693-700.

11 Yang $\mathrm{C}-\mathrm{H}$, Chang W-T, Chuang $\mathrm{H}-\mathrm{Y}$, et al. Adverse health effects among household waste collectors in Taiwan. Environ Res 2001;85:195-9.

12 Cloutier $\mathbf{E}$. The effect of age on safety and work practices among domestic trash collectors in Québec. Safety Science 1994;17:291-308.

13 Lund T, Iversen L, Poulsen KB. Work environment factors, health, lifestyle and marital status as predictors of job change and early retirement in physically heavy occupations. Am J Ind Med 2001;40:161-9. 
14 Stassen ARA, Markslag AMT, FringsDresen MHW, et al. Arbeidsbelasting van huisvuilbeladers bii reinigingsdiensten: conclusies, richtliinen en aanbevelingen [in Dutch]. The Hague: Sdu Uitgeverij Plantijnstraat, 1993.

15 Kuijer PPFM. Effectiveness of interventions to reduce workload in refuse collectors (PhD thesis). Coronel Institute for Work, Environment \& Health, AMCOGG: Center for Research into Health and Health Care, Academic Medical Centre/ University of Amsterdam, 2002.

16 De Looze MP, Stassen ARA, Markslag AMT, et al Mechanical loading on the low back in three methods of refuse collecting. Ergonomics 1995;38: 1993-2006.

17 Schibye B, Sogaard K, Martinsen D, et al. Mechanical load on the low back and shoulders during pushing and pulling of two-wheeled waste containers compared with lifting and carrying of bags and bins. Clin Biomech 2001;16:549-59.

18 Laursen B, Schibye B. The effect of different surfaces on biomechanical loading of shoulder and lumbar spine during pushing and pulling of two-wheeled containers. Appl Ergon 2002;33:167-74.

19 Kuijer PPFM, Hoozemans MJM, Kingma l, et al. Effect of a redesigned two-wheeled container for refuse collecting on mechanical loading of low back and shoulders. Ergonomics 2003:46:543-60.

20 Hoozemans MJM, Van der Beek AJ, FringsDresen MHW, et al. Low-back and shoulder complaints among workers with pushing and pulling tasks. Scand J Work Environ Health 2002;28:293-303.

21 Bovenzi M, Hulshof CTJ. An updated review of epidemiologic studies on the relationship between exposure to whole-body vibration and low back pain (1986-1997). Int Arch Occup Environ Health 1999:72:351-65.

22 Schibye B, Christensen $\mathrm{H}$. The workload during waste collection and meat cutting among workers in different age groups. Arbete och Hälsa 1997;29:272-8.

23 Dos Anjos LA, Ferreira JA. Brazilian legislation regarding physiological workload should be revised! The case of garbage collectors in Rio de Janeiro [in Portuguese]. Cad Saúde Pública, Rio de Janeiro 2000;16:785-90.

24 Sigsgaard T, Malmros P, Nersting L, et al. Respiratory disorders and atopy in Danish refuse workers. Am J Respir Crit Care Med 1994; 149:1407-12

25 Thorn J, Beijer L, Rylander R. Airways inflammation and glucan exposure among household waste collectors. Am J Ind Med 1998;33:463-70.

26 Wouters IM, Hilhorst SKM, Kleppe P, et al. Upper airway inflammation and respiratory symptoms in domestic waste collectors. Occup Environ Med 2002;59:106-12.

27 Heldal KK, Halstensen AS, Thorn J, et al. Upper airway inflammation in waste handlers exposed to bioaerosols. Occup Environ Med 2003;60:444-50.

28 Ivens UI, Ebbehoj N, Poulsen OM, et al. Season, equipment, and job function related to gastrointestinal problems in waste collectors. Occup Environ Med 1997;54:861-7.

29 Ivens UI, Breum NO, Ebbehoj N, et al. Exposureresponse relationship between gastrointestinal problems among waste collectors and bioaerosol exposure. Scand J Work Environ Health 1999;25:238-45.

30 Frings-Dresen MHW, Kemper HCG, Stassen ARA et al. Guidelines for energetic load in three methods of refuse collecting. Ergonomics 1995;38:2056-64.

31 Kuijer PPFM, Visser B, Kemper HCG. Job rotation as a factor in reducing physical workload at a refuse collecting department. Ergonomics 1999;42:1 167-78.

32 Kuijer PPFM, Frings-Dresen MHW, Van der Beek $A J$, et al. Effect of the number of two-wheeled containers at a gathering point on the energetic workload and work efficiency in refuse collecting. Appl Ergon 2002;33:571-7.

33 Kingma I, Kuijer PPFM, Hoozemans MJM, et al. Effect of design of two-wheeled containers on mechanical loading. Int $J$ Ind Ergon 2003;31:73-86

34 Luttmann A, Laurig W, Jäger M. Logistical and ergonomic transportation capacity for refuse collection workers: a work physiology field study. Ergonomics 1992;35:1045-61.

35 Bos J, Kuijer PPFM, Frings-Dresen MHW. Definition and assessment of specific occupational demands concerning lifting, pushing and pulling based on a systematic literature search. Occup Environ Med 2002;59:800-6. 